\title{
Erratum to: Analysis of Machining and Machine Tools
}

\author{
Steven Y. Liang and Albert J. Shih
}

\section{Erratum to:}

\section{S. Y. Liang, A. J. Shih, Analysis of Machining and Machine Tools, DOI 10.1007/978-1-4899-7645-1}

The authors found the following errors in the published volume:

1. Chapter 3, Page 42, $1^{\text {st }}$ line of Question 5: "face milling" should read "end milling"

2. Chapter 4, Page 50, Line number 8: "the volume of metal removed from a soft wheel" should read "the volume of wear from a soft wheel"

3. Chapter 4, Page 52, $2^{\text {nd }}$ line of Example: "The infeed used was $0.3 \times 10^{3}$ in." should read "The infeed used was $0.3 \times 10^{-3}$ in."

The online version of the original book can be found under DOI 10.1007/978-1-4899-7645-1

Steven Y. Liang $(\bowtie)$

George W. Woodruff School of Mechanical Engineering,

Georgia Institute of Technology,

Atlanta, Georgia

USA

e-mail: steven.liang@me.gatech.edu

Albert J. Shih

Mechanical Engineering,

University of Michigan,

Ann Arbor, Michigan

USA

e-mail: shiha@umich.edu 